\title{
Co-solvent effect in the processing of the perovskite:fullerene blend films for electron transport layer-free solar cells
}

\author{
Jorge Pascual, ${ }^{[a, b]}$ Ivet Kosta, ${ }^{[b]}$ Elisa Palacios-Lidon, ${ }^{[c]}$ Andrey Chuvilin, ${ }^{[d, f]}$ Giulia Grancini, ${ }^{[e]}$ \\ Mohammad Khaja Nazeeruddin, ${ }^{[\mathrm{e}]}$ Hans J. Grande, ${ }^{[\mathrm{b}, \mathrm{g}]}$ Juan Luis Delgado, ${ }^{*[\mathrm{a}, \mathrm{f}]}$ Ramón Tena-Zaera ${ }^{*[\mathrm{~b}]}$
}

\begin{abstract}
An understanding of the improvements achieved for the use of co-solvents for methylammonium lead triiodide $\left(\mathrm{MAPbl}_{3}\right):[70]$ fullerene blend films $\left(\mathrm{MAPbl}_{3}: \mathrm{C}_{70}\right)$ processing is presented. A comparative study by using aromatic (i.e., o-xylene and $o$-dichlorobenzene) and aliphatic (i.e., methylcyclohexane and chlorocyclohexane) co-solvents proves the nature of the co-solvent interacting with fullerene to be determining for achieving enhanced devices. UV-Vis spectra of the different [70]fullerene solutions suggest major impact of the solute-aromatic solvent interactions on the optoelectronic properties. The effect of aromatic and aliphatic solvents in the electronic structure of [70]fullerene crystals, obtained from the different solutions, is indeed demonstrated by Electron Energy Loss Spectroscopy. Morphological studies show elimination of pinholes (Field Emission Scanning Electron Microscopy) and different nanometric features related to fullerene (Atomic Force Microscopy) in $\mathrm{MAPbl}_{3}: \mathrm{C}_{70}$ blend films processed by using aromatic co-solvents. A severe quenching of the perovskite emission is observed, suggesting that electron transfer happens from $\mathrm{MAPbl}_{3}$ to $\mathrm{C}_{70}$ [fullerene] in the $\mathrm{MAPbl}_{3}: \mathrm{C}_{70}$ blend films. Furthermore, a faster charge transfer seems to occur in blend films processed by using aromatic co-solvents.
\end{abstract}

[a] J. Pascual, Dr. I. Kosta, Dr. H.G. Grande, Dr. R. Tena-Zaera IK4-CIDETEC

Parque Tecnológico de San Sebastián

Paseo Miramón 196, Donostia-San Sebastián 20009 (Spain)

E-mail: rtena@cidetec.es

[b] J. Pascual, Prof. J. L. Delgado

POLYMAT, University of the Basque Country UPV/EHU

Avenida de Tolosa 72, Donostia-San Sebastián 20018 (Spain)

E-mail: juanluis.delgado@polymat.eu

[c] Prof. E. Palacios-Lidon

Universidad de Murcia, Facultad de Química, Departamento Física Campus Espinardo, Murcia 30100 (Spain)

[d] Prof. A. Chuvilin

CIC nanoGUNE Consolider

Donostia-San Sebastián 20018 (Spain)

[e] Dr. G. Grancini, Prof. Md. K. Nazeeruddin

Ecole Polytechnique Fédérale Lausanne Valais Wallis

Sion $\mathrm{CH}-1951$ (Switzerland)

[f] Prof. A. Chuvilin, Prof. J. L. Delgado

Ikerbasque, Basque Foundation for Science

Bilbao 48013 (Spain)

[g] Dr. H. J. Grande

POLYMAT, Polymer Science and Technology Department, Faculty of Chemistry, University of the Basque Country (UPV/EHU), 20018 Donostia-San Sebastian, Spain

Supporting information for this article is given via a link at the end of the document.

\section{Introduction}

Solution-processed hybrid perovskite solar cells (PSCs) have recently become one of the fundamental pillars in photovoltaic (PV) research, since the preceding discovery of full solid-state halide perovskite solar cells. ${ }^{[1,2]}$ Their unique optoelectronic properties and soft processing conditions ${ }^{[3]}$ have brought these compounds to overtake, in power conversion efficiency (PCE) terms, previously developed all-organic photovoltaics ${ }^{[4]}$ and dye sensitized solar cells. ${ }^{[5]}$

The impact of the hybrid perovskite solar cells in the PV field has been unconditional, mainly due to the exceptionally quick improvement in PCE. ${ }^{[6]}$ One of the key aspects for their success has been their ability to capitalize on over 20 years of development of enhanced selective charge-transport materials. However, this still resembles a field requiring further progress. ${ }^{[7]}$ In this regard, carbon allotropes, and more in particular, fullerenes are a family of molecules that has shown high versatility in photovoltaic technology. ${ }^{[8]}$ Since the first use of $\mathrm{C}_{60}$ as electron transporting layer (ETL) in inverted PSCs by Jeng et al., ${ }^{[9]}$ many studies over their application in several perovskite solar cell architectures have been reported. ${ }^{[10]}$

More in particular, perovskite:fullerene blend films have recently shown outstanding results in PSCs. Xu and colleagues introduced these blends for the first time on regular architectures with a perovskite- $\mathrm{PC}_{61} \mathrm{BM}$ formulation. ${ }^{[11]}$ An elimination of the photocurrent hysteresis was achieved, emulating the devices with fullerenes as charge transporting layers. ${ }^{[12]} \mathrm{PC}_{61} \mathrm{BM}$ fullerene-containing blends were also used by Liu and coworkers for the development of low-cost devices, ${ }^{[13]}$ and by Ran et al. as 1D nanorods in inverted architectures, which led to an enlarged grain size and a more uniform thickness. ${ }^{[14]}$ Perovskite:fullerene complex formulations are currently cutting edge in blends for PSCs. In this sense, high fill factor (FF) values were also achieved through perovskite: $\mathrm{PC}_{61} \mathrm{BM}$ blend films in the work by Chiang and co-workers, finding also a reduction in photocurrent hysteresis. ${ }^{[17]}$ Furthermore, a record FF in PSCs (86.7\%) was achieved by Wang and colleagues by using an innovative, carboxylic acid-substituted fullerene derivative. ${ }^{[15]}$ Moreover, a cross-linkable [60]fullerene derivative was recently used through this strategy for the improvement of performance and stability, pointing out the high potential of these molecules on bulk-heterojunction architectures. ${ }^{[16]}$ Nevertheless, these blends are not restricted to fullerenes with $\mathrm{C}_{60}$ template. Indeed, Pascual and colleagues managed to introduce $\mathrm{C}_{70}$ into perovskite:fullerene blends for improved performance, morphology and photostability in ETL-free devices. ${ }^{[18]}$ The combination of [70]fullerene with o-xylene as co-solvent led to highly improved PSCs in terms of morphology, photostability and efficiency. This co-solvent strategy was later extended to a 
variety of innovative LUMO-tailored fullerenes, actually reaching the state of the art in ETL-free devices with > 14\% PCE values. ${ }^{[19]}$

The use of different solvents in the perovskite solution has been applied in a wider variety of studies though. $N, N$ Dimethylformamide (DMF), dimethyl sulfoxide (DMSO), $N$ methyl-2-pyrrolidone and $y$-butyrolactone are the most common examples for perovskite processing. These solvents and many others have been combined for the improvement of perovskite solution-processing, leading to more efficient devices through the formation of more uniform and dense perovskite films. ${ }^{[20]}$ The addition or combination of different solvents in perovskite processing may be critical so as to achieve successful results.

In this paper, the effect of co-solvent use in lead triiodide perovskite $\left(\mathrm{MAPbl}_{3}\right)$ and $\mathrm{MAPbl}_{3}:[70]$ fullerene blend solutions is presented. The good results obtained for these perovskite films directly deposited over fluorine-doped tin oxide (i.e., glass/FTO/MAPbl 3 :[70]fullerene/spiro-OMeTAD/Au) make this strategy particularly appealing for unraveling its insights. A variety of co-solvents with certain patterns are employed, considering the possible relevance of the co-solvent:fullerene interactions in device performance. PV results and the discussion of the parameters obtained for each co-solvent are combined with further spectroscopic and microstructural characterization. In addition, optical study by means of photoluminescence analysis has been performed monitoring the differences among the samples with and without co-solvent. Some practical guidelines for the choice of an appropriate cosolvent are also discussed.

\section{Results and Discussion}

\section{Solar cells}

$\mathrm{PbCl}_{2}, \quad \mathrm{MAI}, \quad$ and $\mathrm{C}_{70}$-containing $\mathrm{N}, \mathrm{N}$-dimethylformamide (DMF):co-solvent (4:1)-based formulations (see details in Experimental Section) were used to deposit films on glass/FTO substrates. Due to the improved performance obtained in our previous studies with $o$-xylene, ${ }^{[18,19]}$ it was set as reference for co-solvent comparison. Methylcyclohexane (Me-Cy) was chosen as aliphatic equivalent and, for further comparison with other substituents, o-dichlorobenzene (o-DCB) and chlorocyclohexane (Cl-Cy) were chosen as a second aromatic-aliphatic pair (Figure 1). Table 1 summarizes some physico-chemical properties of relevance for the processing of $\mathrm{MAPb}_{3}: \mathrm{C}_{70}$ for the four cosolvents. The effect of these co-solvents was studied for the ETL-free architecture glass/FTO/MAPbl $3: \mathrm{C}_{70}$ :co-solvent (DMF 4:1 co-solvent) and with spiro-OMeTAD and $\mathrm{Au}$ as holeselective and back contact, respectively. Several devices were prepared with each co-solvent for statistical comparison.

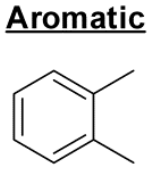

Aliphatic<smiles>CC1CCCCC1</smiles>

\section{Co-solvent \\ $1: 4$ \\ DMF}<smiles>Clc1ccccc1Cl</smiles>

CI

Figure 1. Molecular structure of studied co-solvents for the processing of PSCs.

Table 1. Physico-chemical properties of relevance for selected solvents.

\begin{tabular}{lccc}
\hline Solvent & $d\left(\mathrm{mg} \mathrm{mL}^{-1}\right)$ & b.p. $\left({ }^{\circ} \mathrm{C}\right)$ & $\mu$ \\
\hline o-Xylene & 0.88 & 111 & 0.62 \\
o-DCB & 1.30 & 181 & 2.27 \\
Me-Cy & 0.77 & 101 & - \\
Cl-Cy & 1.00 & 142 & -
\end{tabular}

It has to be noted that all 4 co-solvents do show different effect on solar cells, pointing out their relevance in the perovskite:fullerene film processing conditions. According to the mean values reported in Table 2 for each processing conditions, the highest PV parameters were obtained for aromatic cosolvents (i.e., o-xylene and $o-\mathrm{DCB}$ ). Excluding the lower shortcircuit current density obtained for 0 -DCB, open-circuit voltage $\left(V_{o c}\right)$ and fill factor (FF) were positively affected by the use of any of these two co-solvents, which meant an improvement in comparison to co-solvent-free processed perovskite. On the other side, aliphatic co-solvents did not show any significant difference to co-solvent-free strategy. Me-Cy provided similar mean values, although with a smaller deviation than no-cosolvent formulations. In the case of $\mathrm{Cl}-\mathrm{Cy}$ worse results were obtained though. Still better than fullerene-free devices, a negative effect was found for the application of $\mathrm{Cl}-\mathrm{Cy}$ as cosolvent in [70]fullerene-containing devices (Figure S1-3).

Table 2. Average photovoltaic parameters values for solar cells processed in the different studied conditions.

\begin{tabular}{lcccc}
\hline $\begin{array}{l}\text { Processing } \\
\text { conditions }\end{array}$ & $J_{s c}\left(\mathrm{~mA} \mathrm{~cm}^{-2}\right)$ & $V_{o c}(\mathrm{mV})$ & $\mathrm{FF}(\%)$ & PCE (\%) \\
\hline o-Xylene:C & & & & \\
o-DCB:C $_{70}$ & 16.1 & 1044 & 71.9 & $12.2(13.6)$ \\
Me-Cy:C & 14.4 & 1049 & 74.4 & $11.2(12.0)$ \\
Cl-Cy:C & 15.4 & 1031 & 68.6 & $10.9(11.4)$ \\
C $_{70}$ & 15.1 & 1008 & 64.8 & $9.8(10.8)$ \\
Fullerene-free & 15.3 & 1022 & 68.1 & $10.4(12.0)$ \\
\hline
\end{tabular}

[a] Maximum PCE value for each condition provided in brackets. 


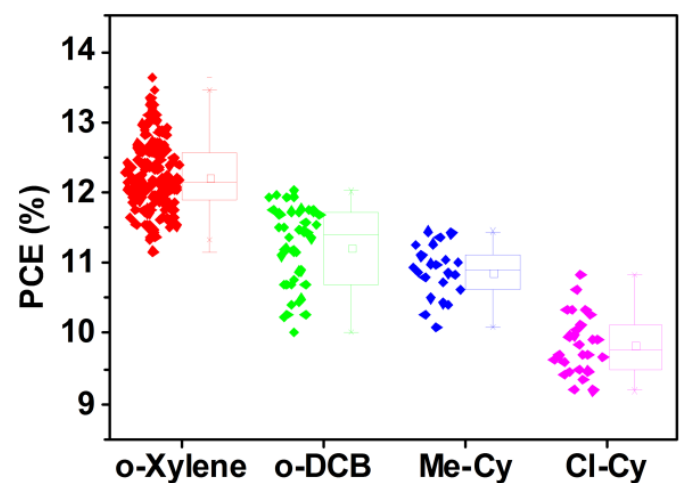

Figure 2. PCE values for each co-solvent used in [70]fullerene-containing PSCs processing.

In Table 2, the most interesting observation can be made on the increase of FF for aromatic co-solvents. In fact, high mean values were obtained for them (i.e., > 70\%), in contrast to aliphatic co-solvents, which provided no improvement over cosolvent-free devices. As shown in Figure 3, it is the presence of $\mathrm{C}_{70}$ that provided an improvement of $\mathrm{FF}$ value; aromatic cosolvents by themselves did not result in any FF difference to cosolvent free devices. Thus, only the combination of the aromatic co-solvents with [70]fullerene in perovskite blends led to highly improved FF values (narrower dispersion is also noted). Indeed, a highest value of $77.5 \%$ was recorded for 0 -DCB, which is comparable to the highest reported value in ETL-free devices. ${ }^{[19]}$

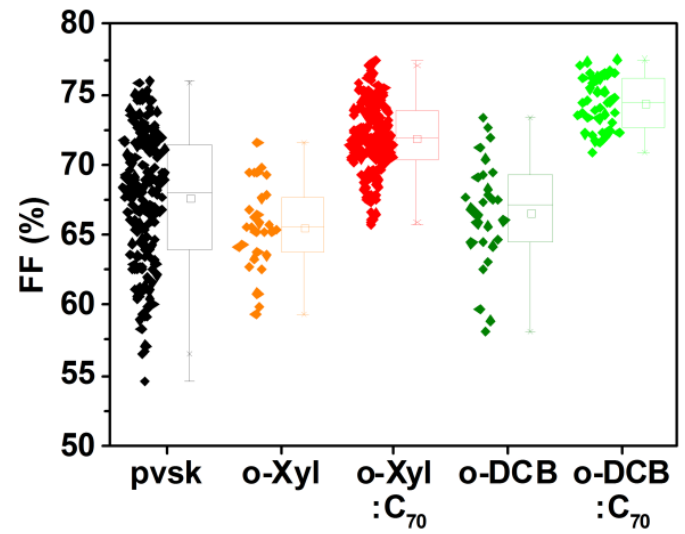

Figure 3. Change in FF when [70]fullerene also used in co-solvent-processed PSCs.

All in all, higher PCE values were reached for aromatic cosolvents (Figure 2). If each pair is studied separately, aromatics led to more efficient devices in contrast to their corresponding aliphatic analogue. Not only that, although exhibiting physicochemical properties such as boiling point, density and polarity in the opposite extremes among the selected solvents (Table 1), both o-xylene and o-DCB provided the most efficient cells. Furthermore, the pair with alkyl substituents provided higher efficiencies overall, in comparison to the halogenated pair (i.e., $o$-xylene vs o-DCB and Me-Cy vs $\mathrm{Cl}-\mathrm{Cy}$ ), suggesting that this feature is more beneficial for co-solvent strategy. It is noted that no differences in PCE were found among the four co-solvents when fullerene was not introduced (Figure S4). This finding points out the beneficial effect of aromatic co-solvent only when used in the presence of [70]fullerene.

The differences presented in Figure 3 claimed thus for an explanation implying some interaction between the co-solvents and [70]fullerene. In this regard, UV-Vis absorption spectra of $\mathrm{C}_{70}$ dissolved in the four studied co-solvents $\left(0.008 \mathrm{mg} \mathrm{mL}^{-1}\right)$ show clear differences between aromatic and aliphatic ones (Figure 4). The main band at $300 \mathrm{~nm}$ is shifted to higher energy values for aliphatic co-solvents, while the bands in the 300-500 $\mathrm{nm}$ range show very low intensity for aliphatics in comparison to aromatics.

The strong bathochromic effect that can be seen for the highest energy band in aromatic solvents has particular interest, pointing out a charge transfer interaction between fullerene and solvent molecule. [70]fullerene has high electron affinity, ${ }^{[21]}$ therefore it can establish relevant charge transfer interactions with an aromatic solvent. ${ }^{[22]}$ Indeed, fullerenes and their excited state may be stabilized through solvent-solute m-stacking. In this regard, strong solute-solvent interactions may compete with solute-solute interactions that produce aggregation of fullerenes. In case of aromatic solvents, more negative enthalpy values are achieved, leading to a greater solvation and therefore less aggregation of fullerene molecules. ${ }^{[23]}$ Therefore, stronger interactions of $o$-xylene and $o$-DCB with this carbon allotrope may be possible due to the $\pi$-delocalization all over the [70]fullerene-ball.

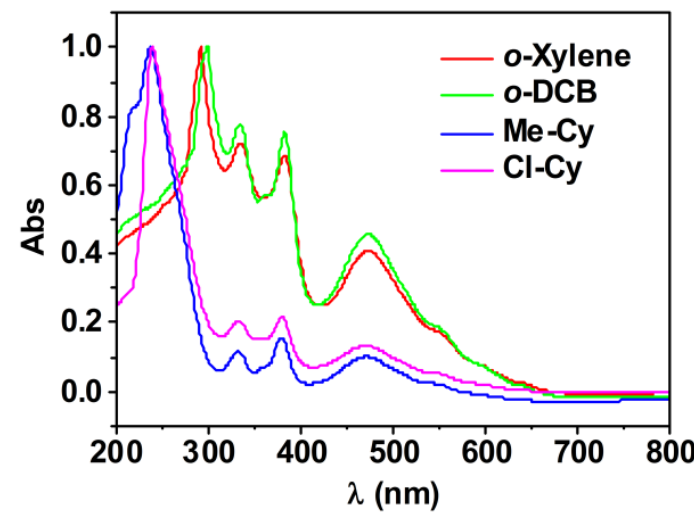

Figure 4. UV-Vis absorption spectra for [70]fullerene dissolved in each studied co-solvent in $0.008 \mathrm{mg} \mathrm{mL}^{-1}$ concentration.

Interestingly, very significant differences in the UV-Vis absorbance spectra of [70]fullerene DMF solution were detected when aromatic co-solvents were used (Figure S5-6). The 
relative position of the absorption peaks of the DMF:co-solvent mixture versus to the ones of pure DMF and co-solvent may provide insights into which solvent is promoting more significant changes in the electronic structure (i.e. in energy diagram too) of the [70]fullerene when interacting with it. Therefore, if the absorption features in the 4:1 mixture are closer in wavelength position to pure co-solvent rather than to pure DMF, then the co-solvent may be the main responsible for solvation of [70]fullerene in the mixture. The [70]fullerene strongest absorbing band position in these spectra was detected closer to its position in pure solutions of co-solvent when used mixtures of DMF:aromatic, but was found closer to its position in DMF when using aliphatic co-solvents (Figure 5). This suggests that in these 4:1 mixtures [70]fullerene experiences major effects in the energy diagram for aromatic co-solvents, but less important ones with aliphatic ones, which agrees with the higher solvation of [70]fullerene with aromatic co-solvents proposed before. ${ }^{[23]}$

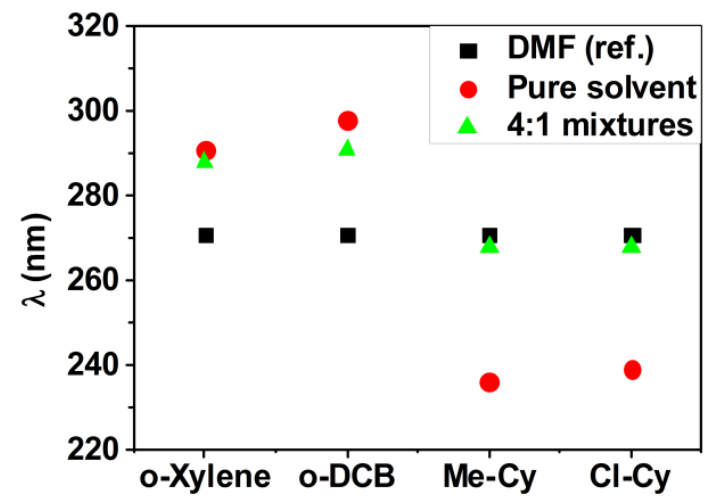

Figure 5. Wavelength position for the strongest UV-Vis absorbing band for DMF, pure co-solvents and 4:1 mixtures.

It is noted that the emission spectra of [70]fullerene solutions also change depending on the co-solvent (Figures 57-8). Excitation at low energy-wavelength values when dissolved in o-xylene (i.e., aromatic) led to very little emission in comparison to Me-Cy (i.e., aliphatic). The relatively minor emission may be due to stronger electronic interactions between aromatic cosolvents and fullerene, making possible non-radiative pathways for the excited-state fullerene electrons.

The influence of the solvent on the electronic structure of [70]fullerene was studied by electron energy loss spectroscopy (EELS). As can be seen in Figure 6, significant peak broadening was detected for [70]fullerene crystals obtained from the solutions of the solvents used in this study when compared to the sublimated film. This indicates that the electron structure of [70]fullerene is significantly influenced by these solvents, which in turn means a strong interaction of the fullerene cages with solvent molecules even in the crystalline state. Strong interaction with the solvent is not a general feature for all solvents, e.g. [70]fullerene crystallized from $\mathrm{CS}_{2}$ solutions shows EELS spectra ${ }^{[24]}$ identical to sublimated films (see comparison of the spectra on Figure S9). Furthermore, the fact that X-Ray
Diffraction (XRD) revealed the formation of different crystal structures when crystallized from different solvents (Figure S10), may point to inclusion of substantial amount of solvent into the crystals due to strong interaction of solvent molecules with [70]fullerene.

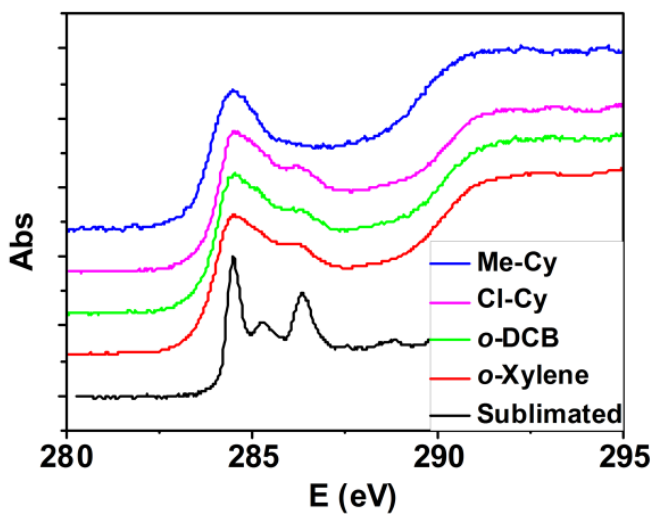

Figure 6. EELS spectra of [70]fullerene processed from different solvents in comparison to sublimated film.

Therefore, the above characterization of the fullerene solutions and processed solid material, respectively, pointed out the existence of significant interactions between the [70]fullerene and the here studied solvents, with major effects on the optoelectronic properties for the aromatic solvents. The effect of these interactions on the perovskite:fullerene film properties were also analyzed.

Figure 7 compares the top-view FE-SEM micrographs of the perovskite:[70]fullerene blend films processed with the different co-solvents. The pinhole-free morphology detected in films processed from formulations including o-xylene and o-DCB suggests that aromatic co-solvents helped to achieve very homogeneous perovskite layers, whilst aliphatic ones led to a high density of pinholes. The pinhole-free nature may indeed be one of the main origins of FF improvement in the solar cells.
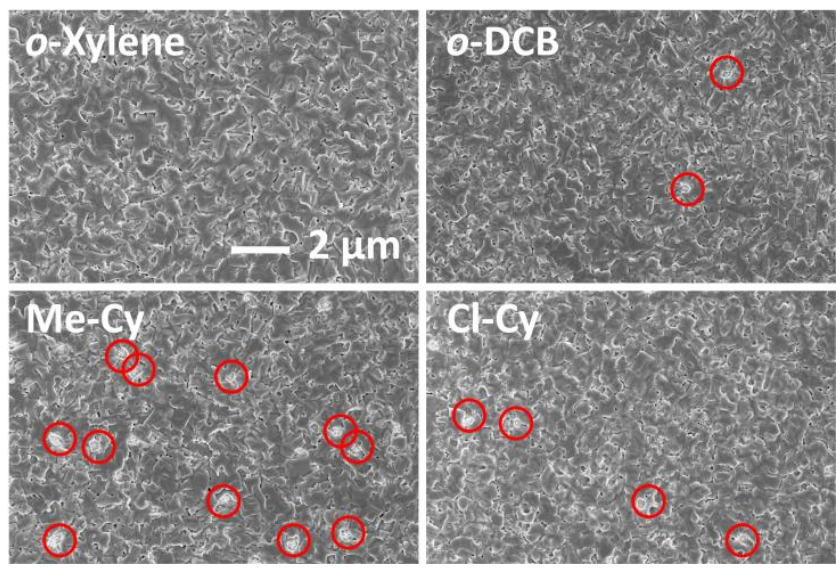

Figure 7. Top-view FE-SEM micrographs of $\mathrm{MAPbl}_{3}: \mathrm{C}_{70}$ blend films processed by using studied co-solvents. 
Further morphological characterization of the perovskite:[70]fullerene films was carried out by Atomic Force Microscopy (AFM). As can be seen in Figure 8a, the overall topography seemed to be independent of the co-solvent nature. However, a detailed high magnification inspection revealed important morphological differences in topography and phase micrographs (Figure 8b), suggesting local chemical composition variations. Aromatic co-solvents (i.e., o-xylene and o-DCB) induced the formation of small island-like regions randomly distributed within the grains with a different chemical composition. However, the use of aliphatic co-solvents led to more homogeneous grains with stepped edges.

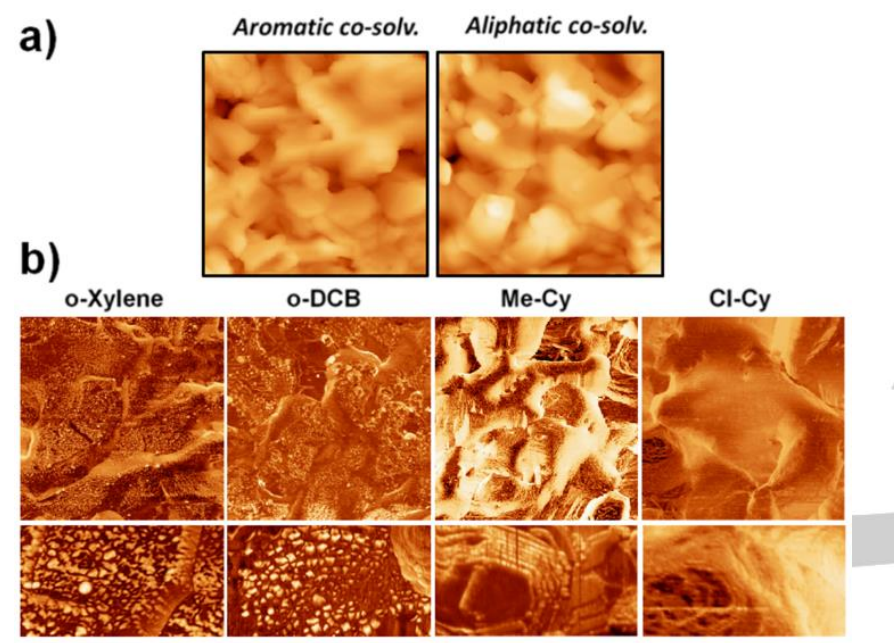

Figure 8. AFM results showing differences in a) low magnification topography images (lateral size $4 \mu \mathrm{m} \times 4 \mu \mathrm{m}$ and $z$ scale $=600 \mathrm{~nm}$ ) and b) high magnification phase images of perovskite:[70]fullerene blend layers processed with each studied co-solvent (top pannels $2 \mu \mathrm{m} \times 2 \mu \mathrm{m}$ and bottom pannels $500 \mathrm{~nm} \times 375 \mathrm{~nm})$.

The optical properties of the perovskite:[70]fullerene films were also investigated by steady state photoluminescence $(\mathrm{PL})$. Figure 9a compares the $\mathrm{PL}$ spectra of glass/MAPbl $3: \mathrm{C}_{70}$ using the o-xylene co-solvent and glass/MAPbl${ }_{3}$ reference samples, respectively. Composite films including fullerene exhibited a quenched $\mathrm{PL}$ emission, suggesting that an efficient charge transfer to [70]fullerene occurs. Note that the excitation used has been tuned to $650 \mathrm{~nm}$, in order to avoid direct excitation of the fullerene. In addition, time-resolved emission kinetics were monitored to gain further insights into the charge dynamics. As shown in Figure 9b, the glass/MAPbl 3 reference sample shows, in good agreement with previous reports, ${ }^{[25]}$ a long-living signal for which the decay is beyond of the experimental time window limit. On the other side, the emission of the MAPbl $3: \mathrm{C}_{70}$ blend films was visibly quenched. In particular, according to the biexponential fit, a fast component (i.e., shorter than $1 \mathrm{~ns}$, limited by the instrument response, see Table S1) is observed. This component can be due to electron transfer happening from $\mathrm{MAPbl}_{3}$ to $\mathrm{C}_{70}$ in the blend film. Note that the excitation density in this case is around $50 \mathrm{~nJ} \mathrm{~cm}{ }^{-2}$, corresponding to $10^{17} \mathrm{~cm}^{-3}$ carrier density generated in the perovskite film. At such fluence, it has been proven that the traps are filled and the emission mainly reflects the electron hole recombination in a purely bimolecular regime. ${ }^{[26]}$ This enables us to suggest the opening of a new channel due to electron transfer. Notably, the same time was indeed found for glass $/ \mathrm{C}_{70} / \mathrm{MAPbl}_{3}$ bi-layer architecture samples (i.e., including $\mathrm{C}_{70} / \mathrm{MAPbl}_{3}$ planar heterostructure) when excited from the [70]fullerene film. Furthermore, longer lifetimes were detected for bilayer samples when excitation was done from the $\mathrm{MAPbl}_{3}$ film (Figure S11 and Table S1), similarly to the pristine $\mathrm{MAPbl}_{3}$. Therefore, perovskite:fullerene blend films appear to be appealing candidates to favor the electron transfer dynamics (i.e., avoiding thickness limitations may occur in bilayer architectures). Interestingly, $\mathrm{MAPbl}_{3}: \mathrm{C}_{70}$ blend films processed by using 0 -xylene exhibited significantly faster decay than those obtained from Me-Cy (i.e., faster component $<1$ ns vs $2.7 \mathrm{~ns}$ ). Therefore, the use of aromatic co-solvents seems to play a beneficial impact on the charge transfer dynamics. This may be due to the differences in the energy diagram (i.e., pointed out by the absorption spectra) and consequent additional pathways for the electron transfer from the $\mathrm{MAPbl}_{3}$ conduction band to the [70]fullerene. However, this does not reflect in huge differences in the $\mathrm{PL}$ emission of glass/MAPbl $3: \mathrm{C}_{70}$ samples processed by using the different cosolvents were detected (Figure S12). Nevertheless, further analysis is subject of ongoing investigations. a)

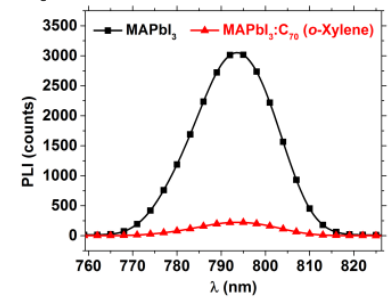

b)

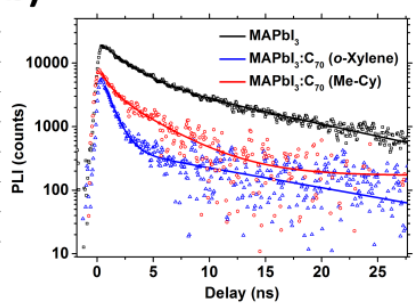

Figure 9. a) Steady-state PL spectra at excitation at $650 \mathrm{~nm}$ and b) PL decays of glass $/ \mathrm{MAPbl}_{3}$ and glass/MAPbl $3: \mathrm{C}_{70}$ samples, excitation at $460 \mathrm{~nm}$, fluence $50 \mathrm{~nJ} / \mathrm{cm}^{2}$. The biexponential fits are also shown. The co-solvent used in the preparation of the $\mathrm{MAPbl}_{3}: \mathrm{C}_{70}$ films is include in parenthesis. Thin films were deposited on glass and encapsulated either with PMMA or with a thin glass film to protect against water or oxygen effect.

\section{Conclusions}

Insights on the beneficial effect of aromatic co-solvent use for the processing of $\mathrm{MAPbl}_{3}: \mathrm{C}_{70}$ blend films and their use in ETLfree solar cells are provided. The use of two differently substituted aromatic co-solvents in 1:4 ratio vs DMF in the perovskite: $\mathrm{C}_{70}$ blend solution lead to enhanced photovoltaic peroformance, whilst no clear evidence of improvement is found for the aliphatic equivalent co-solvents. Moreover, improvements are achieved only if [70]fullerene present. The reason for the relevance of the aromaticity in the co-solvent structure is unraveled by spectroscopic and microscopic techniques. UV-Vis spectra reveal clear differences in band intensities and wavelength values, suggesting stronger optoelectronic impact of solute-solvent interactions for aromatic co-solvents through $\pi-$ 
stacking. The influence of solvent interactions in the electronic structure of the [70]fullerene have been confirmed by EELS. Furthermore, the formation of different crystal structures, suggested by XRD patterns, points to the inclusion of substantial amount of solvent into the crystal lattice as a further evidence of strong interactions between the solvent molecules and [70]fullerene. Microscopic methods also indicated differences in perovskite layers depending on the studied processing conditions. First, FE-SEM results showed a decrease in the number of pinholes for perovskite layers processed with aromatic co-solvents. Also, important morphological variations are seen by AFM, suggesting distinct fullerene distributions in perovskite layer that might be due to the differences in the fullerene-co-solvent interactions. According to time resolved PL measurements, which revealed faster charge transfer dynamics in $\mathrm{MAPbl}_{3}: \mathrm{C}_{70}$ blend films versus pristine $\mathrm{MAPbl}_{3}$, faster electron transfer seems to happen for blend films processed with aromatic co-solvents. In conclusion, the present study allows us to understand the good results obtained through the combination of fullerenes and aromatic co-solvents for ETL-free PSCs, paving the way for further integration of fullerenes in these devices.

\section{Experimental Section}

\section{Materials}

The materials used in this study were obtained from commercial suppliers in high purity and used without further purification: glass/FTO (TEC15, Hartford Glass), $\mathrm{C}_{70}$ (99\%, SES Research), MAI (DYESOL), $\mathrm{PbCl}_{2}$ (98\%, Sigma-Aldrich), spiro-OMeTAD (99\%, Feiming Chemicals Limited), lithium bis(trifluoromethane) sulfonimidate (LiTFSI, 99.9\%, Solvionic), tert-butylpyridine (96\%, Sigma-Aldrich), DMF (extra pure, Scharlab), 2-propanol (synthetic grade, Scharlab), acetone (technical grade, Scharlab), chlorobenzene (99.8\%, Sigma-Aldrich), o-xylene (98\%, SigmaAldrich), o-dichlorobenzene (99\%, Sigma-Aldrich), methylcyclohexane (99\%, Sigma-Aldrich), chlorocyclohexcane (99\%, Sigma-Aldrich) and acetonitrile (UV HPLC grade, Scharlab).

\section{Device fabrication}

Glass/FTO samples were cleaned by the following procedure: the samples were sonicated in distilled water with soap for 5 min, rinsed thoroughly with distilled water, dried, and sonicated in acetone and 2-propanol for $15 \mathrm{~min}$ in each solvent.

The perovskite solution was prepared by dissolving $7.71 \mathrm{mmol}$ of MAl and $2.57 \mathrm{mmol}$ of $\mathrm{PbCl}_{2}$ (molar ratio $3: 1$ ) in $3 \mathrm{~mL}$ of DMF and stirring overnight. Prior to deposition, the $\mathrm{C}_{70}$ was added to the perovskite solution in a 1:4320 ratio. Different co-solvents (i.e., o-xylene, o-dichlorobenzene, methylcyclohexane, chlorocyclohexane) were added to perovskite solution in a 1:4 vs DMF. The resulting solution was spin coated on the substrates following a two-step protocol, which consisted of a first step of
$500 \mathrm{rpm}$ for $5 \mathrm{~s}$ followed by a second step of $2000 \mathrm{rpm}$ for $45 \mathrm{~s}$. Subsequently, the samples were annealed at $100^{\circ} \mathrm{C}$ for $2 \mathrm{~h}$ to ensure complete perovskite formation.

On top of the perovskite layer, the spiro-OMeTAD hole-selective contact was deposited from a solution that contained spiroOMeTAD (108.4 mg) in chlorobenzene (953.43 $\mu \mathrm{L}$ ), LiTFSI solution in $\mathrm{MeCN}\left(17.17 \mu \mathrm{L}, 520 \mathrm{mg} \mathrm{mL}^{-1}\right)$, and tertbutylpyridine $(29.4 \mu \mathrm{L})$. The HTL was deposited by spin coating the solution at $3000 \mathrm{rpm}$ for $30 \mathrm{~s}$. The samples were left in a desiccator overnight. Finally, an array of round Au back contacts $\left(\sim 0.07 \mathrm{~cm}^{2}\right)$ was deposited by thermal evaporation at more than $5 \times 10^{-6}$ torr with a NANO38 (Kurt J. Lesker) apparatus with a shadow mask.

\section{Thin film and device characterization}

The morphological properties of the films were characterized by Field Emission Scanning Electron Microcospy using an ULTRA plus ZEISS FE-SEM. Atomic Force Microscopy (AFM) measurement were performed using a Nanotec S.L microscope operated at room temperature and under nitrogen atmosphere to prevent sample degradation. Topography and phase images were simultaneously acquired using Tapping Mode with silicon tips (OMCL- AC240TS-R3) with nominal force constant $3 \mathrm{~N} / \mathrm{m}$ and $\mathrm{f}=70 \mathrm{KHz}$. Freely available WSxM software has been used for image acquisition and processing. ${ }^{[27]}$ Photoluminescence (PL) characterization (i.e., CW and time-resolved PL experiments) of the films was also performed with a spectrophotometer (Gilden Photonics) using the lamp or a pulsed source at $460 \mathrm{~nm}$ (Ps diode lasers BDS-SM, pulse duration < $100 \mathrm{ps}$, from Photonic Solutions, $20 \mathrm{MHz}$ repetition rate, approx. $500 \mu \mathrm{m}$ spot radius), respectively. The excitation density was around $50 \mathrm{~nJ} \mathrm{~cm}^{-2}$. The steady state spectra and the time-resolved signal were recorded by a photomultiplier tube and by a Time Correlated Single Photon Counting detection technique with a time resolution of $1 \mathrm{~ns}$, respectively. A monoexponential and bi-exponential fitting were used to analyze the background-corrected PL decay signal.

Samples for XRD and TEM were prepared by drying $C_{70}$ solutions in the different solvents $\left(0.5 \mathrm{mg} \mathrm{mL}^{-1}\right)$ on thin glass slides for XRD and $15 \mathrm{~nm}$ silicon nitrate membranes (Ted Pella Inc). After drying, the samples were heated in Ar atmosphere at $100^{\circ} \mathrm{C}$ for $2 \mathrm{~h}$. Sublimated $\mathrm{C}_{70}$ sample was deposited by sublimation in UHV chamber onto a cleaved $\mathrm{KCl}$ monocrystal at $150^{\circ} \mathrm{C}$ substrate temperature. $50 \mathrm{~nm}$ thick deposited film was then floated onto the surface of double distilled water and fished onto a standard lacey carbon TEM grid.

EELS characterization was performed on Titan 60-300 TEM (FEI, Netherlands) equipped with monochromator and Quantum GIF (Gatan, USA). Monochromator was tuned according to the work by Lopatin and co-workers ${ }^{[28]}$ and resolution of $90 \mathrm{meV}$ (full width at half maximum of zero loss peak) at $25 \mathrm{meV} / \mathrm{pixel}$ dispersion was obtained. Spectra were acquired in diffraction 
mode with close to parallel illumination with acceptance angle of 2.8 mrad.

The $J-V$ characteristics of the solar cells were measured under a xenon arc lamp simulator equipped with an AM1.5G spectral filter (Sun 2000, ABET Technologies). The intensity was adjusted to provide 1 sun illumination $\left(100 \mathrm{~mW} \mathrm{~cm}^{-2}\right)$ by using a calibrated silicon solar cell. Unless otherwise mentioned, the $J$ $V$ characteristics were recorded by scanning the potential from higher than the $V_{o c}$ to zero (i.e., "reverse mode") at approximately $300 \mathrm{mV} \mathrm{s}^{-1}$. Before the measurement, a voltage of approximately $1.2 \mathrm{~V}$ was applied to the devices for $1 \mathrm{~min}$.

\section{Acknowledgements}

This work was partially supported by Basque Government (PC2015-1-03 (16-79)) and MINECO of Spain (Grant Numbers MAT2013-47192-C3-2-R, CTQ2015-70921 and ENE201679282-C5-4-R). J.P. acknowledge Polymat for PhD research grant. J.L.D. acknowledges Ikerbasque, the Basque Foundation for Science, for an "Ikerbasque Research Fellow" contract, Polymat Foundation and MINECO of Spain for IEDI-2015-00666 grant. J.P. and J.L.D. acknowledge Iberdrola Foundation for financial support. G.G. is supported by the SNSF Ambizione Energy grant SNF project PZENP2_173641. We acknowledge Ainhoa Atxabal for $\mathrm{C}_{70}$ sublimated sample.

Keywords: fullerenes • solvent • perovskite:fullerene blend films - solar cells • ETL-free

[1] H.-S. Kim, C.-R. Lee, J.-H. Im, K.-B. Lee, T. Moehl, A. Marchioro, S.-J Moon, R. Humphry-Baker, J.-H. Yum, J. E. Moser, M. Grätzel, N.-G. Park, Sci. Rep. 2012, 2, 591.

[2] M. M. Lee, J. Teuscher, T. Miyasaka, T. N. Murakami, H. J. Snaith, Science 2012, 338, 643-647.

[3] a) J. S. Manser, J. A. Christians, P. V. Kamat, Chem. Rev. 2016, 116, 12956-13008; b) S. Collavini, S. F. Völker, J. L. Delgado, Angew. Chem. Int. Ed. 2015, 54, 9757-9759.

[4] a) S. M. Ryno, M. K. Ravva, X. Chen, H. Li, J.-L. Brédas, Adv. Energy Mater. 2016, 1601370; b) C. Cui, Y. Li, Y. Li, Adv. Energy Mater. 2016 1601251 ; c) J. L. Delgado, P.-A. Bouit, S. Filippone, M. A. Herranz, N. Martín, Chem. Commun. 2010, 46, 4853.

[5] a) A. Hagfeldt, G. Boschloo, L. Sun, L. Kloo, H. Pettersson, Chem. Rev. 2010, 110, 6595; b) S. Wenger, P.-A. Bouit, Q. Chen, J. Teuscher, D. Di Censo, R. Humphry-Baker, J. E. Moser, J. L. Delgado, N. Martin, S. M. Zakeeruddin, M. Grätzel, J. Am. Chem. Soc. 2010, 132, 5164; c) B. Xu, H. Tian, L. Lin, D. Qian, H. Chen, J. Zhang, Adv. Energy Mater. 2015, 5, 1401185.

[6] a) Best research-cell efficiencies (National Renewable Energy Laboratory, NREL): http://www.nrel.gov/pv/assets/images/efficiencychart.png; b) M.- H. Li, P.-S. Shen, K.-C. Wang, T.-F. Guoa, P. Chen, J. Mater. Chem. A 2015, 3, 9011-9019; c) S. Collavini, J. L. Delgado, Adv. Energy Mater. 2016, 1601000; d) N. H. Tiep, Z. Ku, H. J. Fan, Adv. Energy Mater. 2016, 6, 1501420.

[7] a) L. Cabau, I. Garcia-Benito, A. Molina-Ontoria, N. F. Montcada, N. Martín, A. Vidal-Ferran, E. Palomares, Chem. Commun. 2015, 51 13980-13982; b) A. Molina-Ontoria, I. Zimmermann, I. Garcia-Benito, P. Gratia, C. Roldán-Carmona, S. Aghazada, M. Grätzel, M. K.
Nazeeruddin, N. Martín, Angew. Chem. Int. Ed. 2016, 55, 6270; c) H. Li, K. Fu, P. P. Boix, L. H. Wong, A. Hagfeldt, M. Grätzel, S. G. Mhaisalkar, A. C. Grimsdale, ChemSusChem 2014, 12, 3420-3425; d) S. F. Völker, S. Collavini, J. L. Delgado, ChemSusChem 2015, 8, 3012; e) S. Ameen, M. A. Rub, S. A. Kosa, K. A. Alamry, M. S. Akhtar, H.-S. Shin, H.-K. Seo, A. M. Asiri, M. K. Nazeeruddin, ChemSusChem 2016, 9, 10-27.

[8] a) Y. He, H.-Y. Chen, J. Hou, Y. Li, J. Am. Chem. Soc. 2010, 132, 1377-1382; b) G. Zhao , Y. He, Y. Li, Adv. Mater. 2010, 22, 4355-4358.

[9] J.-Y. Jeng, Y.-F. Chiang, M.-H. Lee, S.-R. Peng, T.-F. Guo, P. Chen, T.-C. Wen, Adv. Mater. 2013, 25, 3727-3732.

[10] a) C.-Y. Chang, W.-K. Huang, Y.-C. Chang, K.-T. Lee, C.-T. Chen, J. Mater. Chem. A 2016, 4, 640; b) O. Malinkiewicz, A. Yella, Y. H. Lee, G. M. Espallargas, M. Grätzel, M. K. Nazeeruddin, H. J. Bolink, Nat. Photon. 2014, 8, 128-132; c) H. Azimi, T. Ameri, H. Zhang, Y. Hou, C O. R. Quiroz, J. Min, M. Hu, Z.-G. Zhang, T. Przybilla, G. J. Matt, E. Spiecker, Y. Li, C. J. Brabec, Adv. Energy Mater. 2015, 1401692; d) X. Liu, W. Jiao, M. Lei, Y. Zhou, B. Song, Y. Li, J. Mater. Chem. A 2015, 3, 9278; e) C. Tian, K. Kochiss, E. Castro, G. Betancourt-Solis, H. Han, L. Echegoyen, J. Mater. Chem. A 2017, 5, 7326-7332; f) Y. Bai, Q. Dong, Y. Shao, Y. Deng, Q. Wang, L. Shen, D. Wang, W. Wei, J. Huang, Nat. Commun. 2016, 7, 12806; g) Q. Xue, Y. Bai, M. Liu, R. Xia, Z. Hu, Z. Chen, X.-F. Jiang, F. Huang, S. Yang, Y. Matsuo, H.-L. Yip, Y. Cao, Adv. Energy Mater. 2017, 1602333; h) S. Collavini, I. Kosta, S. F Völker, G. Cabanero, H. J. Grande, R. Tena-Zaera, J. L. Delgado, ChemSusChem 2016, 9, 1263-1270; i) W. Ke, D. Zhao, C. R. Grice, A J. Cimaroli, J. Ge, H. Tao, H. Lei, G. Fang, Y. Yan, J. Mater. Chem. A 2015, 3, 17971; j) Y. Li, Y. Zhao, Q. Chen, Y. M. Yang, Y. Liu, Z. Hong, Z. Liu, Y.-T. Hsieh, L. Meng, Y. Li, Y. Yang, J. Am. Chem. Soc. 2015, 137, 15540-15547; k) Z. Wang, D. P. McMeekin, N. Sakai, S. van Reenen, K. Wojciechowski, J. B. Patel, M. B. Johnston, H. J. Snaith, Adv. Mater. 2017, 29, 1604186.

[11] J. Xu, A. Buin, A. H. Ip, W. Li, O. Voznyy, R. Comin, M. Yuan, S. Jeon, Z. Ning, J. J. McDowell, P. Kanjanaboos, J.-P. Sun, X. Lan, L. N. Quan, D. H. Kim, I. G. Hill, P. Maksymovych, E. H. Sargent, Nat. Commun. 2015, 6, 7081

[12] Y. Shao, Z. Xiao, C. Bi, Y. Yuan, J. Huang, Nat. Commun. 2014, 5, 5784 .

[13] C. Liu, K. Wang, P. Du, C. Yi, T. Meng, X. Gong, Adv. Energy Mater. 2015, 1402024

[14] C. Ran, Y. Chen, W. Gao, M. Wang, L. Dai, J. Mater. Chem. A 2016, 4, 8566-8572.

[15] K. Wang, C. Liu, P. Du, J. Zheng, X. Gong, Energy Environ. Sci. 2015 8, 1245.

[16] M. Li, Y.-H. Chao, T. Kang, Z.-K. Wang, Y.-G. Yang, S.-L. Feng, Y. Hu X.-Y. Gao, L.-S. Liao, C.-S. Hsu, J. Mater. Chem. A 2016, 4, 1508815094.

[17] C.-H. Chiang, C.-G. Wu, Nat. Photon. 2016, 10, 196-200.

[18] J. Pascual, I. Kosta, N. Tuyen, A. Chuvilin, G. Cabanero, H. J. Grande, E. M. Barea, I. Mora-Seró, J. L. Delgado, R. Tena-Zaera ChemSusChem 2016, 18, 2679-2685.

[19] R. Sandoval-Torrientes, J. Pascual, I. García-Benito, S. Collavini, I. Kosta, R. Tena-Zaera, N. Martín, J. L. Delgado, ChemSusChem 2017 9, 2023-2029.

[20] a) N. J. Jeon, J. H. Noh, Y. C. Kim, W. S. Yang, S. Ryu, S. I. Seok, Nat. Mater. 2014, 13, 897-903; b) H. Chen, Z. Wei, H. He, X. Zheng, K. S. Wong, S. Yang, Adv. Energy Mater. 2016, 6, 1502087; c) Y. Rong, Z. Tang, Y. Zhao, X. Zhong, S. Venkatesan, H. Graham, M. Patton, Y. Jing, A. M. Guloy, Y. Yao, Nanoscale 2015, 7, 10595-10599; d) Y. Tu, J. Wu, X. He, P. Guo, T. Wu, H. Luo, Q. Liu, K. Wang, J. Lin, M. Huang, Y. Huang, Z. Lan, S. Li, J. Mater. Chem. A 2017, 5, 43764383.

[21] N. O. Mchedlov-Petrossyan, Chem. Rev. 2013, 113, 5149-5193.

[22] I. Renge, J. Phys. Chem. 1995, 99, 15955-15962.

[23] S. H. Gallagher, R. S. Armstrong, P. A. Lay, C. A. Reed, J. Phys. Chem 1995, 99, 5817-5825. 
[24] S. M. Lee, R. J. Nicholls, D. Nguyen-Manh, D. G. Pettifor, G. A. D. Briggs, S. Lazar, D. A. Pankhurst, D. J. H. Cockayne, Chem. Phys. Lett 2005, 404, 206-211.

[25] C. Roldán-Carmona, P. Gratia, I. Zimmermann, G. Grancini, P. Gao, M. Graetzel, M. K. Nazeeruddin, Energy Environ. Sci. 2015, 8, 3550.
[26] S. D. Stranks, V. M. Burlakov, T. Leijtens, J. M. Ball, A. Goriely, H. J. Snaith, Phys. Rev. Applied 2014, 2, 034007.

[27] I. Horcas, R. Fernandez, J. M. Gomez-Rodriguez, J. Colchero, J. Gomez-Herrero, A. M. Baro, Rev. Sci. Instrum. 2007, 78, 013705.

[28] S. Lopatin, B. Cheng, W.-T. Liu, M.-L. Tsai, Jr-H. He, A. Chuvilin, Ultramicroscopy 2018, 184 109-115. 


\section{FULL PAPER}

Further insights into the interactions between co-solvents and [70]fullerene: beneficial effects of using aromatic solvents in the processing of the $\mathrm{CH}_{3} \mathrm{NH}_{3} \mathrm{Pbl}_{3}$ : [70]fullerene blend films and enhanced performance in perovskite solar cells.

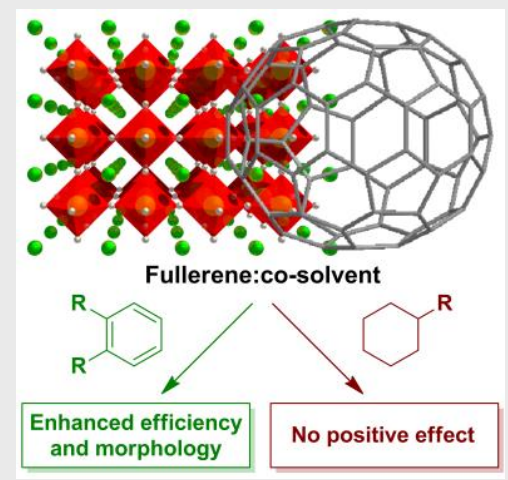

J. Pascual, I. Kosta, E. Palacios-Lidon, A. Chuvilin, G. Grancini, M. K. Nazeeruddin, H. J. Grande, J. L. Delgado, ${ }^{\star} R$. Tena-Zaera*

\section{Page No. - Page No.}

Co-solvent effect in the processing of the perovskite:fullerene blend films for electron transport layer-free solar cells 